\title{
1 An efficient optimization of well placement and 2 control for a geothermal prospect under geological uncertainty
}

6 Mingjie Chen ${ }^{\mathrm{ab}} *$, Andrew F.B. Tompson ${ }^{\mathrm{a}}$, Robert J. Mellors ${ }^{\mathrm{a}}$, and Osman

$9 \quad{ }^{a}$ Atmospheric, Earth and Energy Division, Lawrence Livermore National

10 Laboratory, Livermore, CA, USA

11 bater Research Center, Sultan Qaboos University, Muscat, Oman

$14 *$ Corresponding author:

16 Mingjie Chen, $\mathrm{PhD}$

17 Water Research Center

18 Sultan Qaboos University

19 P.O.Box 17, P.C. 123

20 Al Khoud, Sultanate of Oman

22 968-24143202 (office)

23 cmj1014@yahoo.com

24 chen70@llnl.gov

25 mingjie@squ.edu.om 


\section{Abstract}

27 This study applies an efficient optimization technique based on a multivariate

28 adaptive regression spline (MARS) technique to determine the optimal design and

29 engineering of a potential geothermal production operation at a prospect near Superstition

30 Mountain in Southern California, USA. The faster MARS-based statistical model is used

31 as a surrogate for higher-fidelity physical models within the intensive optimization

32 process. Its use allows for the exploration of the impacts of specific engineering design

33 parameters in the context of geologic uncertainty as a means to both understand and

34 maximize profitability of the production operation. The MARS model is initially

35 developed from a training dataset generated by a finite set of computationally complex

36 hydrothermal models applied to the prospect. Its application reveals that the optimal

37 engineering design variables can differ considerably assuming different choices of

38 hydrothermal flow properties, which, in turn, indicates the importance of reducing the

39 uncertainty of key geologic properties. The major uncertainty sources in the natural-

40 system are identified and ranked first by an efficient MARS-enabled total order

41 sensitivity quantification, which is then used to assist evaluating the effect of geological

42 uncertainties on optimized results. At the Southern California prospect, this parameter

43 sensitivity analysis suggests that groundwater circulation through high permeable

44 structures, rather than heat conduction through impermeable granite, is the primary heat

45 transfer method during geothermal extraction. Reservoir histories simulated using

46 optimal parameters with different constraints are analyzed and compared to investigate

47 the longevity and maximum profit of the geothermal resources. The comparison shows

48 that the longevity and profit are very likely to be overestimated by optimizations without 
49 appropriate constraints on natural conditions. In addition to geothermal energy

50 production, this optimization approach can also be used to manage other geologic

51 resource operations, such as hydrocarbon production or $\mathrm{CO} 2$ sequestration, under

52 uncertain reservoir conditions.

54 Keywords: geothermal; surrogate; optimization; uncertainty; sensitivity

\section{Introduction}

57 Reinjection of geothermal fluids into geothermal reservoirs has been demonstrated as

58 an essential practice for increasing the productive lifetime of reservoirs and recovery of

59 thermal energy. Re-injection helps to maintain pressure in the geothermal reservoirs,

60 slow down production declines in response to pressure drawdown [1], and, as a result,

61 extent the period of time over which useful thermal energy can be recovered. The

62 development and management of geothermal fields is complicated and expensive and

63 maximum potential geothermal energy recovery depends on optimal well location and

64 operation $[2,3]$. Simulation-based optimization methods can address these problems by

65 utilizing production and economic models to evolve favorable production designs and

66 strategies through the minimization of one or more quantitative physical or economic

67 objective functions. Often, these approaches may require a large number of intensive

68 forward model simulations, which may quickly become impractical because of their

69 substantial computational burden. As an alternative, a simpler and approximate

70 "surrogate model" may be constructed as a means to provide a faster simulation of the

71 physical system, which may potentially benefit an optimization or sensitivity-based 
72 analysis that would otherwise requires thousands or more of iterative geothermal

73 production simulations. Surrogate or "response surface" models that relate input variables

74 to output responses are developed through the use of statistical models that are fitted by

75 training datasets generated by a finite set of more complex physical simulation models.

76 Surrogate-based optimization approaches have been extensively studied and advanced in

77 the past decade in various application fields [4-11]. Widely used surrogate model

78 techniques in hydrology include polynomial regression, kriging, radial basis functions,

79 sparse grid interpolation, support vector machines, and artificial neural networks [12-14].

80 Here, we consider the Multivariate Adaptive Regression Spline (MARS) technique as

81 developed by Friedman [15] more than two decades ago and routinely used in automatic

82 engineering design [16]. MARS is a nonparametric regression technique that adaptively

83 develops local models in local regions for flexible regression modeling of high

84 dimensional data. Each local model is represented by a basis function and an associated

85 coefficient to be determined. Comparative studies have shown that MARS is superior to

86 other high dimensional regression methods (e.g. polynomials) in accuracy and reduction

87 in computational cost of fitting process [4,17].

88 Optimal development and management of a geothermal reservoir will call for an

89 accurate understanding of reservoir behavior under both natural and engineered

90 conditions. However, for geothermal optimization problems, there are a variety of

91 uncertainties associated with the rock properties and structural features of the formation

92 that may significantly affect the optimized results. Assessment of these effects on

93 optimal well placement and control will assist development and management of a

94 geothermal reservoir. 
95 This study couples a complex hydrothermal simulation model and a MARS-based

96 surrogate model to investigate the effects of geological uncertainties (fault size,

97 geological unit permeability) on optimal well placement and control (re-injection well

98 location, production rate) in a geothermal prospect near Superstition Mountain in

99 Southern California, USA. Comparative optimization cases are implemented using prior

100 and posterior probability distributions of geological parameters, which are adapted from a

101 previous study on a MARS-based Bayesian inversion [18] to represent maximal and

102 reduced geological uncertainties respectively. To evaluate the influence of uncertainties

103 of individual geological properties on optimal results, additional optimization

104 experiments are designed and conducted by sequentially fixing the uncertain geological

105 parameters during optimizing process.

\section{2. MARS-based optimization framework}

107 The MARS-based optimization framework consists of several steps that include:

108 Conceptual design and parametric definition of the hydrothermal flow system of interest,

109 including ranges in uncertain geological properties and operational parameters to be

110 optimized; Development of physical hydrothermal flow models for this system;

111 Construction and validation of a MARS surrogate model through the generation and

112 processing of training data drawn from these steps; and Application of the MARS

113 surrogate models in the optimization process to minimize objective functions. As

114 illustrated in Figure 1, these steps involve the MARS-based optimization proceeds as

115 follows:

116 1. Conceptual Design of the Surrogate: The conceptual model design leads to a series of

117 M uncertain parameters with associated ranges or probability distribution functions 
118 (PDFs), including unknown geological properties and operational parameters to be

119 included in surrogate model. Using a Latin Hypercube (LH) method [19], these are

120 sampled $\mathrm{N}$ times to yield a set of $\mathrm{N}$ training sample vectors. In this study all

121 parameters are assumed to have a uniform-type of PDF.

122 2. Training Data Generation: These $\mathrm{N}$ sample vectors, each with $\mathrm{M}$ components, are

123 used as inputs to develop $\mathrm{N}$ hydrothermal flow models for the system. Here, we

124 utilize the NUFT (Nonisothermal Unsaturated-saturated Flow and Transport) model

125 [20] that considers both initialization (run 1 million year to steady state) and

126 production simulation (run to 1000 years of extraction from the initial natural state).

127 The results of each simulation are used to construct individual model responses, in

128 this case, representing an evaluation of the objective function to be minimized in the

$129 \quad$ optimization process.

130 3. MARS Model Development: In MARS algorithm, local models are adaptively

131 developed in local regions for flexible regression modeling of high dimensional data.

132 The model can be written as $\hat{f}(\mathbf{x})=\sum_{i=1}^{k} a_{i} B_{i}(\mathbf{x})$, where $\mathbf{x} \in \mathcal{R}^{m}$, and $\mathcal{R}^{m}$ is the $m$ -

133 dimensional space. $k$ and $a_{i}$ are the number and coefficients of associated basis

134 functions $B_{i}(\mathbf{x})=\prod_{j=1}^{J_{i}}\left[S_{j i} \cdot\left(x_{v(j, i)}-t_{j i}\right)\right]_{+}, i=1,2,3, \ldots$, where $(\cdot)_{+}=\max (0$,

$135), J_{i}$ is the interaction order of basis $B_{i}$, that is, the number of variables included in the

136 basis function, $S_{j i}= \pm 1$ is the sign indicators, $v(j, i)$ is the index of the design

137 variable $x$ which is split on knots $t_{j i} . a_{i}$ and $B_{i}(\mathbf{x})$ can evaluated after the number of

138 locations of knots is adaptively chosen based on the response function changes. The

$139 \quad \mathrm{~N}$ pairs of sample input vector versus response (objective function) are used to

140 construct a MARS model, as shown in shaded portion of Figure 1. A MARS model 
141 that is fitted well does not necessarily mean it is good for prediction due to potential 142 issues with over-fitting. Following the Leave-One-Out Cross-Validation (LOOCV)

143 method [21], a MARS model is constructed $\mathrm{N}$ times, each time leaving out one of the

144 input samples from training dataset, and using the omitted sample to test the model.

145 The errors between output of NUFT and MARS models with these N inputs are used

146 to evaluate the accuracy of the MARS model. Sobol' total order sensitivity indices

147 [22-23], which represent indicators of uncertainty contribution of each input variable

148 to the response, can also be efficiently calculated using the MARS model.

149 4. MARS-Enabled Optimization: The validated MARS models are coupled with an

150 optimization algorithm to efficiently search for the minimum objective function,

151 along with the corresponding optimal values of input parameters. Specifically, we use

152 Bound Optimization by Quadratic Approximation (BOBYQA), a powerful

153 derivative-free minimization algorithm developed by Powell [24], to drive this

154 bound- constrained nonlinear optimization problem. The most attractive feature of

155 this solver is that it seeks the least value of a function of several input variables

156 without requiring any derivatives of the objective function.

157 The optimization framework is written in Python to drive hydrothermal NUFT model

158 simulations and incorporate necessary algorithms related to LH sampling, MARS

159 approximation, cross-validation, Sobol' sensitivity, and BOBYQA from the Problem

160 Solving environment for Uncertainty Analysis and Design Exploration (PSUADE)

161 package [25].

162 3. Optimization design for Superstition Mountain geothermal prospect 
163 As shown in Figure 2a, the Superstition Mountain Geothermal prospect (SMG) is

164 located near the Salton Sea in Southern California, USA. Geothermal and related

165 geological characterization data for this effort have been drawn from three nearby

166 exploratory boreholes drilled by the U.S. Navy geothermal program [26-27] and other

167 related data and references summarized in [28].

168 3.1. Hydrothermal model development

169 As described in [30, 31], the underlying geological structure in the vicinity of the

170 SMG has been conceptualized from an Earthvision ${ }^{\circledR}$ geologic model based upon data and

171 interpretations summarized in [27, 28]. As illustrated in Figure 2b, the SMG is bounded

172 by Superstition Mountain Fault (SMF), a faulted and fractured granitic basement, and

173 four sandstone and alluvial layers of varied composition and hydraulic permeability.

174 Previous studies of the prospect [26-31] suggest that strong hydrothermal communication

175 exists (and has existed) between deeper high temperatures zones underlying the granite

176 and the generally cooler shallow aquifers. Ground surface observations indicate a

177 confined zone of higher temperatures surrounding the prospect [26-27], evidence of

178 hydrothermal alteration products in surface rocks [29], and borehole temperature profiles

179 indicative of localized hydrothermal groundwater circulation [26-27, 30-31] through low

180 permeable granite zone. A recent numerical model was developed to simulate natural

181 steady state hydrothermal conditions at the prospect through inclusion of a hypothesized

182 vertical conjugate fault (CF; shown in dashed yellow in Figure 2b) normal to SMF and

183 extending to northeast through the NAFEC-3 borehole [18, 30-31]. This model is able to

184 predict steady-state temperatures that closely match temperature logs in the three

185 boreholes. The core model domain shown in Figure $2 b$ is enclosed by a larger far field 
186 domain (Figure 3a) to alleviate boundary effects on the hydrothermal flow in targeted

187 production area, which is adapted as the domain of the hydrothermal models in this study.

188 As shown in Figures 2 and 3, the $\mathrm{X}$-axis of the core domain is parallel to the CF plane,

189 and extends northeast from Superstition Mountain (and the SMF plane) by a distance of

$1906.5 \mathrm{~km}$. The core domain is $1.5 \mathrm{~km}$ wide, transverse to the $\mathrm{CF}$ and parallel to

191 Superstition Mountain (and the SMF plane). The center of the left boundary intersects the

$192 \mathrm{CF}$ plane at right angle. The model domain extends $3.2 \mathrm{~km}$ from the ground surface, and

193 is discretized by $100 \mathrm{~m}$ grid space vertically. The horizontal grid space increases

194 gradually from $100 \mathrm{~m}$ in core region to $8 \mathrm{~km}$ in farthest field to save computational

195 efforts. Representation of geological structures in the model is shown in the vertical cross

196 section parallel with the CF plane in Figure 3b. Here, it can be seen how the geologic

197 units are sequenced from bottom to top as low permeability granite zone overlain by the

198 sandstone (Ti) and alluvial sediment layers (Tp2, $\mathrm{Tp} 1, \mathrm{Qb})$ in a dipping orientation

199 (Figure 3b). The $100 \mathrm{~m}$ thick CF plane is normal to the left boundary, which lies parallel

200 to Superstition Mountain and the SMF plane (Figure 3c). Pressure and temperature

201 conditions are specified along the top boundary to represent the average atmospheric

202 conditions. Similarly, fixed pressure and high temperature conditions are specified along

203 the bottom boundary to represent the geothermal heat source and allow for buoyancy-

204 driven groundwater flow to enter through the bottom of domain. Lateral pressure

205 boundary conditions were specified to induce a small hydraulic gradient parallel with the

$206 \mathrm{X}$-axis of the domain, consistent with local water table observations; Y faces of the

207 domain are maintained as no-flux boundaries. This configuration of boundary conditions

208 will support a hypothesized groundwater circulation pathway in which hot water migrates 
209 vertically into the domain through faulted granite at the bottom, flows laterally through

210 the permeable sandstone unit (Ti), and exits laterally through the right end of the domain.

211 Each hydrothermal model realization considered in the training process (Figure 1)

212 will consist of two sequential hydrothermal simulations; the first is an initialization

213 (steady state) model and the second, a corresponding production (pumping) model. The

214 initialization model considers a particular geologic configuration (parameters and

215 geologic properties) and runs a simulation out to a steady state at one million years,

216 representing an undisturbed natural condition as might be seen today, largely as described

217 in $[30,31]$. The results in this model are then used as initial values for the subsequent

218 production (pumping) model in which simulations are run for another thousand years.

\section{3.2. Production-injection design}

220 Four out of 15 important and uncertain hydrothermal parameters (Table 1) were

221 identified as critical factors influencing temperature distribution in target production zone

222 [18]. These include vertical extent and length of the conjugate fault (CF), its intrinsic

223 hydraulic permeability, and the permeability of the Ti sandstone unit. The uncertainties of

224 these parameters were reduced by an efficient MARS-based Bayesian inference using

225 temperatures observed along the three boreholes (shown in Figure 4) and quantified by

226 the resulting posterior distribution [18, 30, 31] (Figure 5). It is notable that the optimal

227 CF height is peculiarly prone to be $3200 \mathrm{~m}$, at its upper limit, in order to best match the

228 observations, strongly suggesting that the vertical CF plane penetrates the entire

229 impermeable granite zone in order to permit hydraulic contact with the permeable $\mathrm{Ti}$

230 formation. Although the CF height could take on other values with a much smaller

231 probability, it will be fixed as $3200 \mathrm{~m}$ and, thus, excluded from further optimization steps. 
232 The CF length, and log-permeability of the $\mathrm{CF}$ and Ti units are considered randomly

233 distributed within the uniform ranges defined by values indicated by red dotted line in

234 Figure 5. The corresponding lower and upper bounds for the three key parameters are 800

$235 \mathrm{~m}$ and $1600 \mathrm{~m},-13.3$ to $-12.8\left(\mathrm{~m}^{2}\right)$, and -13.8 to $13.3\left(\mathrm{~m}^{2}\right)$, respectively. As shown, the

236 posterior distribution of each parameter, as examined in [18], is reduced to a quarter of

237 the original one; this serves to better constrain the optimization in the next step.

238 Given a specified production well location, the optimization process seeks to locate

239 two injection wells and determine the production well pumping rate to achieve maximum

240 net profit from a potential SMG geothermal operation. The design considerations for the

241 production-injection scheme are shown in Figure 6. The single production well is fixed at

$242 \mathrm{X}=1.3 \mathrm{~km}$ along the central $\mathrm{X}$-axis. The locations of two symmetric injection wells are

243 determined by their common radial distance $R$ from the production well and associated

244 azimuth angle $\alpha$ (clockwise and counterclockwise) away from the central $\mathrm{X}$-axis. $R$ is

245 allowed to vary between 100 to $700 \mathrm{~m}$ while $\alpha$ may range between 0 and $90^{\circ}$. The ranges

246 of $R$ and $\alpha$ lead to a semicircular area of possible locations for the two injection wells

247 (Figure 6). The injection wells are restricted to lie on the down gradient side of the

248 production well because of the presence of the impermeable granite formation on the up

249 gradient side. Besides, the left boundary across Superstition Mountain may act as natural

250 injection source by groundwater recharging when pressure declines around the

251 production well.

252 Both injection and production wells are perforated with a length of $100 \mathrm{~m}$ at the 800

$253 \mathrm{~m}$ depth so that injection or production is operated in the more permeable $\mathrm{CF}$ or $\mathrm{Ti}$

254 formation. The production rate is to be optimized within the range from 1 to $50 \mathrm{~kg} / \mathrm{s}$. To 
255 assure reservoir pressure support, the bottom hole pressures (BHP) of injection wells are

256 fixed as $0.5 \mathrm{MPa}$ less than the background pressure provided by the initialization model,

257 meaning that the reservoir pressure around injection wells are allowed to decline at most

258 by $0.5 \mathrm{MPa}$. As a result, the injection wells act as artesian production wells initially, and

259 are automatically converted to injection wells once the pressures around injection wells

260 fall below the specified BHP. Optimal combination of the six parameters, including the

261 geologic properties and the three operational parameters associated with the injection

262 well placement and control, are to be determined within their bounds to minimize the

263 objective function defined in next subsection.

264 3.3. Objective function

265 The objective for the optimization of production-injection design and control is to

266 maximize the net profit value (NPV) after a specified time of operation (e.g., 50 years).

267 The net profit value represents the value of net energy production minus costs associated 268 with water production and injection, defined specifically as

$$
N P V=(C N T P \times \$ / M W h t)-(C W P \times \$ / p w a t)-(C W I \times \$ / i w a t)(1)
$$

270 where $C N T P, C W P, C W I$ represent the cumulative net thermal energy production,

271 cumulative water production and cumulative injection respectively, which are obtained

272 from outputs of NUFT hydrothermal model simulations (well flux, energy, pressure,

273 temperature, etc.). The quantity $\$ / M W h t$ represents the price of thermal energy per

274 thermal megawatt-hour $(M W h t)$, which is converted from electricity price per electricity

275 megawatt-hour (MWhe). The quantities \$/pwat and \$/iwat are the costs of water

276 production and reinjection per ton respectively. The electricity price, cost of production 
277 and injection, and the conversion factor from $M W h e$ to $M W h t$ can be easily modified in

278 Eq.(1) to accommodate market variation and technique improvements.

279 For the training phase, the six uncertain input parameters, with their ranges, will

280 constitute a six-dimensional data space for LH sampling. A series of 1,000 hydrothermal

281 models (including sequential initialization and production steps) are developed with

282 NUFT. The objective function (NPV) for each model is calculated as a time series from

283 the transient NUFT production phase model outputs. Following the procedure in Figure 1,

284 MARS models are then fitted and validated using the training dataset that consists of

2851000 pairs of input vectors (six components) versus response functions (objective

286 functions evaluated at a series of time steps). The MARS model response surfaces are

287 then used as fast approximations of the objective functions during the optimizing process.

\section{4. Results and discussion}

289 4.1. Optimizations under varying parameter space dimensionality

290 The quality of the MARS models is measured by comparison of the responses to the

291 NUFT model using the 1000 input samples. As shown in Figure 7, the R-square of 1000

292 scatter points determined by objective function values at 50 years of operation made by

293 the NUFT and MARS models is 0.987 and 0.975 for fitting and validation, respectively,

294 indicating that the well-fitted MARS model has a good predictive ability. To investigate

295 how the uncertainty of each individual parameter affects optimized results, six

296 optimization cases defined by sequentially fixing parameter values are performed by

297 coupled execution of the BOBYQA optimizer and the MARS model. The ranges or the

298 fixed values of the six parameters for Cases 1-6, as well as the corresponding results, are 
listed in Table 2. Note additional optimizations with other MARS models in different

300 operational times can be readily executed with BOBYQA if needed.

301 As shown in Table 2, Case 1 searches the full 6-D parameter space to find the

302 minimal objective function (i.e. maximal NPV). This case represents a scenario in which

303 the injection well placement and production well pumping rate are determined under best

304 available reservoir knowledge from Bayesian inversion using the temperature

305 observations [18]. The optimal location of the two injection wells is found as $R=473 \mathrm{~m}$

306 and $\alpha=74^{\circ}$ (Figure 6), and the optimal production well pumping rate is $30.7 \mathrm{~kg} / \mathrm{s}$. The

307 associated three optimal reservoir properties are also obtained, among which the log

308 permeability values of the $\mathrm{CF}$ and Ti units are optimized as -12.92 and $-13.33\left(\mathrm{~m}^{2}\right)$

309 respectively, very close to their upper bounds of -12.8 and $-13.3\left(\mathrm{~m}^{2}\right)$. It makes sense

310 since the $\mathrm{CF}$ and $\mathrm{Ti}$ units form the groundwater circulation pathways, and the optimal

311 values are expected to be as high as possible. The fault length is optimized as $1472 \mathrm{~m}$,

312 larger than $1200 \mathrm{~m}$, which is the minimum value for the CF unit to be physically

313 connected with the Ti unit.

314 Case 2 assumes CF length is already determined as $1200 \mathrm{~m}$, and Case 3 further fixes

315 the CF $\log$ permeability as $-13.16\left(\mathrm{~m}^{2}\right)$, both of which have the highest probability from

316 their posterior PDFs (Figure 2b, 2c). Interestingly, the optimized results between Case 2

317 and 3 are almost the same and optimal azimuth $\alpha$ in both cases increase slightly to $90^{\circ}$

318 from $74^{\circ}$ in Case 1 . This behavior can be explained by the low sensitivity of the CF

319 length (SI < 0.05) and insensitivity of CF permeability (SI < 0.01$)$ for the objective

320 function (Table 2). As expected, the associated maximal NPVs of Case 2 and 3 are

321 reduced to $130.0 \mathrm{M} \$$ and $127.1 \mathrm{M} \$$ from $145.8 \mathrm{M} \$$ in Case 1 , since optimization of Case 
$3223(4-\mathrm{D})$ is conducted in a subspace of Case $2(5-\mathrm{D})$, which in turn is conducted in a

323 subspace of Case $1(6-\mathrm{D})$.

324 Case 4 (3-D) represents an optimization scenario given full knowledge of the SMG

325 site, with all the three geological properties fixed at values with maximal probability from

326 their posterior PDFs. The NPV is substantially decreased to 74.8 from $127.1 \mathrm{M} \$$, and

327 optimal injection-production well distance is shortened to $407 \mathrm{~m}$ by $66 \mathrm{~m}$ from Case 3 .

328 This is reasonable since Ti permeability is moderately sensitive ( $\mathrm{SI}=0.21)$.

329 The comparison of Case 1-4 reveals that reduced uncertainty of CF doesn't influence

330 the optimized results. It makes sense since the height of the CF unit is fixed at $3200 \mathrm{~m}$,

331 and its $\log$ permeability is higher than $-13.3\left(\mathrm{~m}^{2}\right)$, which assures that a high permeable

332 plane penetrates entire impermeable granite. Since the Ti unit serves as the other

333 permeable flow pathway, its $\log$ permeability $\left(\leq-13.3 \mathrm{~m}^{2}\right)$, therefore, becomes relatively

334 important for efficient geothermal extraction. Note both injection and production wells

335 are perforated in the Ti formation.

336 Case 5 (2-D) and 6 (1-D) is designed to compare the optimized production well rate

337 assuming known azimuth $\left(\alpha=45^{\circ}\right)$ and injection location $\left(R=600 \mathrm{~m}, \alpha=45^{\circ}\right)$ respectively.

338 The optimized pumping rate remains almost the same between Cases 5 and 6, which is

339 unexpected considering that the well distance $R$ is sensitive ( $\mathrm{SI}=0.3)$. The visualized

340 response surface for Case 5 shows the contour of the objective function (i.e., negative

341 NPV) with respect to $R$ and rate in Figure 8. It is seen that the minimum area includes $R$

342 from 400 to $600 \mathrm{~m}$ around the rate of $29 \mathrm{~kg} / \mathrm{s}$, explaining the similar optimized rate (28.9

343 and $29 \mathrm{~kg} / \mathrm{s}$ ) between Case 5 (optimal $R=420 \mathrm{~m}$ ) and 6 (constant $R=600 \mathrm{~m}$ ). 
344 Figure 9 depicts the searching history of the minimal objective function for each of

345 the six cases. It is seen that the number of MARS model evaluations required to satisfy

346 the convergence criteria $\left(10^{-6}\right)$ is $297,388,396,359,490$, and 302 for case $1-6$. These

347 hundreds of model evaluations can be completed in seconds, while a single simulation of

348 production NUFT model costs as long as five hours. As a result, this MARS-enabled

349 approach can enable the otherwise computationally intensive procedure to be completed

350 efficiently in the simulation-based optimization. In addition, Figure 8 shows multiple

351 local minimum objective functions existing on a 2-D response surface in Case 5, and the

352 global minimum is successfully found using the BOBYQA optimizer.

\section{4.2. Comparison of optimized results in two sets of parameter ranges}

354 To investigate how optimized results could be affected by the degree of uncertainty in

355 natural hydrogeological conditions, an additional set of MARS surrogate simulations is

356 developed following the procedure in Figure 1 using the information prior to Bayesian

357 inversion (Chen et al., 2014), and the corresponding optimization (denoted as Case 0) is

358 compared to Case 1, which is better constrained by posterior knowledge. The ranges of

359 CF length, CF permeability, and Ti permeability used in Case 0 are three times wider

360 than those in Case 1, and the corresponding optimized results also differ substantially

361 between both cases (Table 3). Parameter sensitivities, which are considered indicators of

362 uncertainty contribution of each input parameter to the response, are visualized in Figure

36310 for the MARS simulations used in both cases. Compared to Case 0 , the sensitivities of

364 CF length, and CF and Ti permeabilities in Case 1 are reduced substantially, while those

365 of azimuth $\alpha$, well distance $R$, and production rate increase moderately. These results are

366 expected, since the uncertainties (ranges) of the three hydrogeological parameters are 
367 greatly reduced from Case 0 to Case 1, and hence the other three well placement and

368 control parameters become relatively more important accordingly.

369 In Case 0, the optimal log-permeabilities of CF and Ti are -12.07 and -13.05 $\left(\mathrm{m}^{2}\right)$

370 respectively, near the upper bound of their ranges, but beyond the ranges in Case 1,

371 which are narrowed by Bayesian inference using field data. This finding not only

372 confirms that a higher permeability of $\mathrm{CF}$ and $\mathrm{Ti}$ is always preferable for thermal

373 production, but also suggests the necessity of reducing uncertainties of reservoir

374 properties prior to optimization. A better constrained natural system in Case 1 can lead to

375 a much different optimal design and operation from those in Case 0. As shown in Table

3763 , the optimal well distance is shortened by $130 \mathrm{~m}$, and the optimal pumping rate is

377 increased from $19.9 \mathrm{~kg} / \mathrm{s}$ in Case 0 to $30.7 \mathrm{~kg} / \mathrm{s}$ in Case 1 . Although the azimuth is also

378 increased greatly by $52^{\circ}$, its variation can be neglected for heat production profit since it

379 is insensitive in both cases (Sensitivity Index, SI $<0.01$ ). The maximal NPV is increased

380 substantially from $145.8 \mathrm{M} \$$ in Case 1 to $241.9 \mathrm{M} \$$ in Case 0 . However, this higher NPV

381 in Case 0 cannot be obtained in practice since the associated optimal $\mathrm{CF}$ and $\mathrm{Ti}$

382 permeability is beyond the more credible ranges in Case 1.

383 4.3. Production-injection history analysis

384 Hydrothermal NUFT model simulations using the optimal parameter sets from Case 0

385 and 1 have been simulated to 1000 years (denoted as Simulation 0 and 1), and the

386 histories of the first 200 and 150 years are shown in Figures 11 and 12 respectively. In

387 Simulation 0 and 1, the BHP of both injection wells in the production models are fixed at

3885.30 and 5.24 MPa, respectively, 0.5 MPa lower than the background pressure from the

389 according initialization models. This initial local lower pressure leads to immediate water 
390 production from the injection wells at the beginning of the production phase. As shown in

391 Figures 11a and 12a, the extraction rates are 36.95 and $15.61 \mathrm{~kg} / \mathrm{s}$, respectively, initially,

392 and decrease as the pressure gradient declines. After 70 years of operation in both

393 simulations, the extraction is converted to injection and the rate keeps increasing to

394 maintain the constant BHP. The cumulative net profit from injection wells are calculated

395 by subtracting cost of extraction or injection operation from the revenue of extracted

396 energy, and is maximized in 70 years (Figure $11 \mathrm{~b}$ and 12b). Figures $11 \mathrm{c}$ and $12 \mathrm{c}$ show

397 that the BHP of production well drops dramatically from 6.16 and $5.81 \mathrm{MPa}$ to 5.27 and

$3984.89 \mathrm{MPa}$, respectively, in one year and then falls gradually to 5.08 and $4.63 \mathrm{MPa}$ in 150

399 years due to constant extraction at 19.9 and $30.7 \mathrm{~kg} / \mathrm{s}$. The extracted water temperature

400 decreases smoothly from initial 160 and $134{ }^{\mathrm{c}} \mathrm{C}$ to 142 and $94{ }^{\mathrm{c}} \mathrm{C}$, respectively, after 150

401 years of operation in Simulation 0 and 1 (Figure 11e and 12e). The cumulative net profit

402 of the production well, which is calculated by subtracting cost of production from the

403 revenue of extracted energy, increases during the entire operation process (Figure 11d

404 and 12d). The history of cumulative net profit values of both production and injection

405 wells, as defined by NPV in Eq. (1), are shown in Figure $11 \mathrm{f}$ and $12 \mathrm{f}$ for both simulations.

406 Although NPV in 50 years is used as the objective to be maximized in the optimization

407 Case 0 and 1, NPV reaches peak in 170 and 130 years, respectively, and falls sharply in

408 each case after each one is reached. It seems that the optimal parameter set from Case 0

409 can lead to a better longevity of the geothermal field and a larger amount of energy than

410 Case 1. The 50-year NPV values simulated by the MARS models for Case 0 and 1 are

411241.9 and $145.8 \mathrm{M} \$$, respectively. When rerun with the NUFT model, the 50-year NPV

412 values are 265.7 and $159.5 \mathrm{M} \$$, respectively, demonstrating a reasonable accuracy of 
413 constructed MARS models and the optimization method. The comparison of Simulation 0

414 and 1 indicates that the longevity and profit are very likely to be overestimated by

415 optimizations without appropriate constraints on natural conditions.

416 It should be noted that the fixed BHP value determines the initial production time of

417 the injection wells. The higher the BHP is, the shorter the production time and the lower

418 the revenue will be. While BHP is fixed as a value 0.5MPa lower than background

419 pressure in previous production simulations, an additional production model (denoted as

420 Simulation 2) is constructed using the optimal parameters from Case 1, but with a

421 decrement of 0.4 MPa from the background pressure. In other words, the fixed BHP in

422 Simulation 2 is $0.1 \mathrm{MPa}$ higher than that in Simulation 1. The resulted histories of

423 Simulation 2 are shown in Figure 13 for comparison with those of Simulation 1 in Figure

424 12. As expected, the initial pumping rate of the injectors is reduced to $9.07 \mathrm{~kg} / \mathrm{s}$, and the

425 time of shifting extracting to injecting operation is shortened to 45 years, when the

426 cumulative revenue from the injection wells reaches the maximum. In contrast to

427 injection wells, the histories of pressure and temperature at production well differ only

428 slightly between Simulation 1 and 2, as well as the resulting revenue from production

429 well. The net cumulative revenue, which is the sum of cumulative revenue from injection

430 and production wells, reach its maximal value of $200 \mathrm{M} \$$ in 90 years, 40 years earlier and

$43165 \mathrm{M} \$$ less than the corresponding time and profit in Simulation 1. The comparisons

432 between Simulation 1 and 2 suggest that a lower fixed BHP of injection wells can extend

433 the longevity and increase the profit of a geothermal field, though the reservoir pressure

434 must be carefully controlled in an appropriate range to assure geomechanical stability. 


\section{Conclusions}

436 The results of this study indicate that coupling multivariate adaptive regression spline

437 (MARS) model and bound optimization by quadratic approximation (BOBYQA)

438 provides an efficient way of reducing computational demand of simulation-based

439 optimization process. Especially in large-scale fields like Superstition Mountain

440 Geothermal prospect, the computational cost of doing an exhaustive search using high-

441 fidelity hydrothermal models is beyond feasible limits, and the proposed MARS-based

442 framework was successfully implemented and a suite of optimization cases under

443 various parameter uncertainty were executed efficiently. The major conclusions are as

444 follows:

445 - The developed optimization framework is highly efficient. A MARS-based

446 optimization case entailing hundreds of model runs could be completed in seconds,

447 while a single high-fidelity model costs hours using the same computing facility.

448 - Given all the available knowledge obtained from both geophysical characterization

449 and Bayesian inversion for Superstition Mountain Geothermal prospect (SMG), the

450 optimal production rate is $30.7 \mathrm{~kg} / \mathrm{s}$ and distance between production and injection

451 well is $473 \mathrm{~m}$ in order to maximize the net profit after 50 years of potential

452 geothermal extraction.

453 - Given different knowledge (uncertainty of input parameters) of the site, the optimized

454 results could be significantly different. Sensitivity analysis could be applied to

455 identify the key parameters where efforts should be focused to reduce the uncertainty.

456 Both geophysical characterization (geological structure, borehole logs) and numerical

457 method (Bayesian inversion) can be used to constrain the optimization. 
- For SMG site, sensitivity analysis shows that water circulation is the primary heat

459 transfer method other than heat conduction through granite zone during production.

460 Well-constrained permeability and width of the granite fault won't influence the

461 optimization results given the fact that the determined $3200 \mathrm{~m}$ height of the fault

462 guaranteed the high permeable plane to penetrate the entire granite zone to contact

463 permeable Ti formation. The shallow Ti formation, therefore, become relatively

464 important for an efficient geothermal production.

465 - History analysis of production simulations using different optimal results reveals that

466 the longevity and profit are very likely to be overestimated by optimizations without

467 appropriate constraints on natural conditions. Bottom hole pressure (BHP) of the

468 injection wells is found to affect the profit substantially, indicating maintaining a

469 balance between pressure support and thermal breakthrough is critical to the

470 geothermal field management. While BHP is fixed in the study, it is better to be

471 treated as an uncertain parameter to investigate its influence on thermal production

$472 \quad$ systematically.

473 - The pumping rate of the production well optimized in this study is constant

474 throughout the production operation, though a time-varying pumping strategy might,

475 in fact, be a more flexible option to control reservoir pressure and maximize profit.

476 The production-injection design could include the varying pumping rate for

477 sequential management periods, and the proposed MARS-based optimization

478 framework could be used to obtain them.

\section{Acknowledgements}


481 Lawrence Livermore National Laboratory under contract DE-AC52-07NA27344. We

482 would like to thank DOE GTO office for supporting this project under award DE-EE24675.

483 We also appreciate the Navy geothermal program for providing data. We also appreciate

484 the valuable comments from the anonymous reviewers and associated editor, which

485 substantially improved the final paper.

\section{References}

[1] Stefansson V. Geothermal reinjection experience. Geothermics 1997;26:99-139.

[2] Procesi M, Cantucci B, Buttinelli M, Armezzani G, Quattrocchi F, Boschi E. Strategic use of the underground in an energy M. mix plan: Synergies among CO2, $\mathrm{CH} 4$ geological storage and geothermal energy. Latium Region case study (Central Italy). Applied Energy 2013;110:104-131. doi: 10.1016/j.apenergy.2013.03.071.

[3] Kaniyal AA, Nathan GJ, Pincus JJ. The potential role of data-centres in enabling investment in geothermal energy. Applied Energy;2013:98:458-466. doi:10.1016/j.apenergy.2012.04.009.

[4] Chen M, Sun Y, Fu P, Carrigan CR, Lu Z, Tong C, Buscheck TA. Surrogate-based optimization of hydraulic fracturing in pre-existing fracture networks. Comput \& Geosciences 2013;58:69-79. doi:10.1016/j.cageo.2013.05.006.

[5] Fen CS, Chan CC, Cheng HC. Assessing a response surface-based optimization approach for soil vapor extraction system design. J Water Resour Plann Manage 2009;135(3): 198-207.

[6] Forrester AIJ, Keane AJ. Recent advances in surrogate-based optimization. P Aerospace Sci 2009;45:50-79. doi:10.1016/j.bbr.2011.03.031.

[7] Queipo NV, Haftka RT, Shyy W, Geol T, Vaidyanathan, R, Tucker PK. Surrogatebased analysis and optimization. P Aerospace Sci 2005;41:1-28. doi: 10.1016/j.paerosci.2005.02.001.

[8] Regis RG, Shoemaker CA. A stochastic radial basis function method for the global optimization of expensive functions. INFORMS J Comput 2007;19(4):497-509.

[9] Sanchez E, Pintos S, Queipo NV. Toward and optimal ensemble of kernel-based approximations with engineering applications, Struct Multidiscip O 2008;36:24761. doi: 10.1007/s00158-007-0159-6.

[10] Simpson TW, Mistree F. Kriging models for global approximation in simulationbased multidisciplinary design optimization, AIAA J 2001;39(12):2233-41.

[11] Wang GG, Shan S. Review of metamodeling techniques in support of engineering design optimization. J of Mech Design 2007;129(4):370-80. doi: 10.1115/1.2429697.

[12] Razavi S, Tolson BA, Burn DH. Review of surrogate modeling in water resources. Water Resour Res 2012;48:W07401. doi:10.1029/2011WR011527. 
[13] Nobile F, Tempone R, Webster CG. A sparse grid stochastic collocation method for elliptic partial differential equations with random input data. SIAM J Numer Anal 2008;46:2309-45.

[14] Zeng L, Shi L, Zhang D, Wu L. A sparse grid based Bayesian method for contaminant source idenficiation. Adv Water Resour 2012;37:1-9.

[15] Friedman JH. Multivariate adaptive regression splines. Ann Stat 1991;19(1):1-67.

[16] Sudjianto A, Juneja L, Agrawal A, Vora M. Computer aided reliability and robustness assessment. Int J Rel Qual Saf Eng 1998;5:181-93. doi: 10.1142/S0218539398000182.

[17] Jin R, Chen W, Simpson TW. Comparative studies of metamodelling techniques under multiple modelling criteria. Struct Multidisc Optim 2001;23:1-13.

[18] Chen M, Tompson AFB, Mellors RJ, Ramirez AL, Dyer KM, Yang X, Wagoner JL. An efficient Bayesian inversion of a geothermal prospect using a multivariate adaptive regression spline method. Under review by Applied Energy 2014.

[19] McKay M, Beckman R, Conover W. A comparison of three methods for selecting values of input variables in the analysis of output from a computer code. Technometrics 1979;21(2):239-45.

[20] Nitao JJ. Reference manual for the NUFT flow and transport code, version 2.0, Technical Report UCRL-MA-130651. Lawrence Livermore National Laboratory, Livermore, CA; 1998.

[21] Picard RR, Cook RD. Cross-validation of regression models. J Am Stat Assoc 1984;79:575-83.

[22] Sobol' IM. Sensitivity estimates for non-linear mathematical models. Math Modeling Comput Exp 1993;4:407-14.

[23] Sobol' IM. Theorems and examples on high dimensional model representation. Reliab Eng Syst Saf 2003;79(2):187-93.

[24] Powell MJD. The BOBYQA algorithm for bound constrained optimization without derivatives, Report DAMTP 2009/NAO6, Centre for Mathematical Sciences, University of Cambridge, UK; 2009.

[25] Tong C. PSUADE (Problem Solving environment for Uncertainty Analysis and Design Exploration) User's Manual (Version 1.2.0). Lawrence Livermore National Laboratory, LLNL-SM-407882; 2009.

[26] Bjornstad S, Hall B, Unruh J, Richards-Dinger K. Geothermal Resource Exploration, NAF El Centro- Superstition Mountain Area, Imperial Valley, California. Geoth Res Council Trans 2006;30.

[27] Tiedeman A, Bjornstad S, Alm S, Frazier L, Meade D, Page C et al. Intermediate depth drilling and geophysical logging results at superstition mountain, Naval Air Facility El Centro, California. Geoth Res Council Trans 2011;35:1037-44.

[28] Tompson AFB, Demir Z, Moran J, Mason D, Wagoner J, Kollet S et al. Groundwater availability within the Salton Sea Basin: Final report, Lawrence Livermore National Laboratory, Livermore, CA; 2008.

[29] Layman Energy Associates, Inc. Superstition Mountain geothermal project. http://laymanenergy.com/Superstition-Mountain.html; 2012.

[30] Mellors RJ, Ramirez AL, Tompson AFB, Chen M, Yang X, Dyer KM et al. Stochastic joint inversion of a geothermal prospect. 38th Workshop on Geothermal Reservoir Engineering Stanford University, Palo Alto, CA, February11-13; 2013. 
564 [31] Tompson AFB, Mellors RJ, Ramirez AL, Chen M, Dyer KM, Yang, X et al. 565 Evaluation of A Geothermal Prospect Using A Stochastic Joint Inversion Modeling Procedure, Geothermal Resources Council Transactions, Volume 36, Geothermal Resources Council Annual Meeting, Las Vegas, NV, USA; September 29 - October $2,2013$. 
Tables and Figures

570 Table 1. Important hydrogeological parameters used in simulation of natural 571 hydrothermal conditions at Superstition Mountain prospect. Model domain is 572 illustrated in Figure 2 and 3, and the simulated temperature contour is shown as 573 background in Figure 3b, 3c.

\begin{tabular}{lcc}
\hline Input parameter set & Value & In optimization \\
\hline Fault height $(\mathrm{m})$ & 3200 & fixed \\
Fault length $(\mathrm{m})$ & 1200 & adjustable \\
Fault log permeability $\left(\mathrm{m}^{2}\right)$ & -13.16 & adjustable \\
Ti log permeability $\left(\mathrm{m}^{2}\right)$ & -13.44 & adjustable \\
Bottom boundary temperature $\left({ }^{\circ} \mathrm{C}\right)$ & 165 & fixed \\
Granite thermal conductivity $(\mathrm{W} / \mathrm{m}-\mathrm{C})$ & 3.0 & fixed \\
Ti thermal conductivity $(\mathrm{W} / \mathrm{m}-\mathrm{C})$ & 2.0 & fixed \\
Granite log permeability $\left(\mathrm{m}^{2}\right)$ & -18 & fixed \\
Fault thermal conductivity $(\mathrm{W} / \mathrm{m}-\mathrm{C})$ & 2.0 & fixed \\
Tp1 thermal conductivity $(\mathrm{W} / \mathrm{m}-\mathrm{C})$ & 0.5 & fixed \\
Tp2 log permeability $\left(\mathrm{m}^{2}\right)$ & -14 & fixed \\
Tp2 thermal conductivity $(\mathrm{W} / \mathrm{m}-\mathrm{C})$ & 0.5 & fixed \\
Tp1 log permeability $\left(\mathrm{m}^{2}\right)$ & -14 & fixed \\
Qb thermal conductivity $(\mathrm{W} / \mathrm{m}-\mathrm{C})$ & 0.5 & fixed \\
Qb log permeability $\left(\mathrm{m}^{2}\right)$ & -14 & fixed \\
\hline
\end{tabular}

Table 2. Parameter set and the optimal values for optimization case 1-6. Injection well location and production well pumping rate are optimized under various uncertainties of other parameters after 50 years of operation.

\begin{tabular}{lcccccccc}
\hline Input parameter & Range & SI & Case 1 & Case 2 & Case 3 & Case 4 & Case 5 & Case 6 \\
\hline Fault length $(\mathrm{m})$ & $800 \sim 1600$ & 0.03 & 1472 & 1200 & 1200 & 1200 & 1200 & 1200 \\
Fault log perm. $\left(\mathrm{m}^{2}\right)$ & $-13.3 \sim-12.8$ & 0.0075 & -12.82 & -12.82 & -13.16 & -13.16 & -13.16 & -13.16 \\
Ti log perm. $\left(\mathrm{m}^{2}\right)$ & $-13.8 \sim-13.3$ & 0.21 & -13.32 & -13.32 & -13.32 & -13.44 & -13.44 & -13.44 \\
Azimuth $\left({ }^{\circ}\right)^{1}$ & $0 \sim 90$ & 0.0082 & 74 & 90 & 90 & 82 & 45 & 45 \\
Well distance $(\mathrm{m}){ }^{1}$ & $100 \sim 700$ & 0.30 & 473 & 473 & 473 & 407 & 417 & 600 \\
Prod. rate $(\mathrm{kg} / \mathrm{s})$ & $1 \sim 50$ & 0.75 & 30.7 & 29.6 & 30.4 & 28.7 & 28.9 & 29.0 \\
\hline Max NPV $(\mathrm{M} \$)$ & & & 145.8 & 130.0 & 127.1 & 74.8 & 74.5 & 66.4 \\
\hline Model evaluation \# & & & 297 & 388 & 396 & 359 & 490 & 302 \\
\hline
\end{tabular}

$579{ }^{1}$ Injection well locations can be determined by injection-production well distance $R$ and azimuth

$580 \alpha$, as illustrated in Figure 5. Gray shaded values are fixed and not included for optimization. 
584 Table 3. Range, optimal values (Opt), and Sobol' total order sensitivity indices (SI) of the parameters for optimization case 0 and case 1 , in which injection well location and production well pumping rate are optimized under prior and posterior range of the three geological parameters after 50 years of operation.

\begin{tabular}{lcccccc}
\hline \multirow{2}{*}{ Input parameter } & \multicolumn{3}{c}{ Case 0 } & \multicolumn{3}{c}{ Case 1 } \\
\cline { 2 - 7 } & Range & SI & Opt & Range & SI & Opt \\
\hline Fault length $(\mathrm{m})$ & $100 \sim 3200$ & 0.094 & 1233 & $800 \sim 1600$ & 0.03 & 1472 \\
Fault log perm. $\left(\mathrm{m}^{2}\right)$ & $-14 \sim-12$ & 0.12 & -12.07 & $-13.3 \sim-12.8$ & 0.0075 & -12.82 \\
Ti log perm. $\left(\mathrm{m}^{2}\right)$ & $-15 \sim-13$ & 0.33 & -13.05 & $-13.8 \sim-13.3$ & 0.21 & -13.32 \\
Azimuth $\left({ }^{\circ}\right)^{1}$ & $0 \sim 90$ & 0.0031 & 22 & $0 \sim 90$ & 0.0082 & 74 \\
Well distance $(\mathrm{m}){ }^{1}$ & $100 \sim 700$ & 0.18 & 603 & $100 \sim 700$ & 0.30 & 473 \\
Prod. rate $(\mathrm{kg} / \mathrm{s})$ & $1 \sim 50$ & 0.64 & 19.9 & $1 \sim 50$ & 0.75 & 30.7 \\
\hline Max NPV $(\mathrm{M} \$)$ & & & 241.9 & & & 145.8 \\
\hline Model evaluation \# & & \multicolumn{7}{c}{272} & & & 297 \\
\hline
\end{tabular}

${ }^{1}$ Injection well locations can be determined by injection-production well distance $R$ and azimuth $\alpha$, as illustrated in Figure 5.

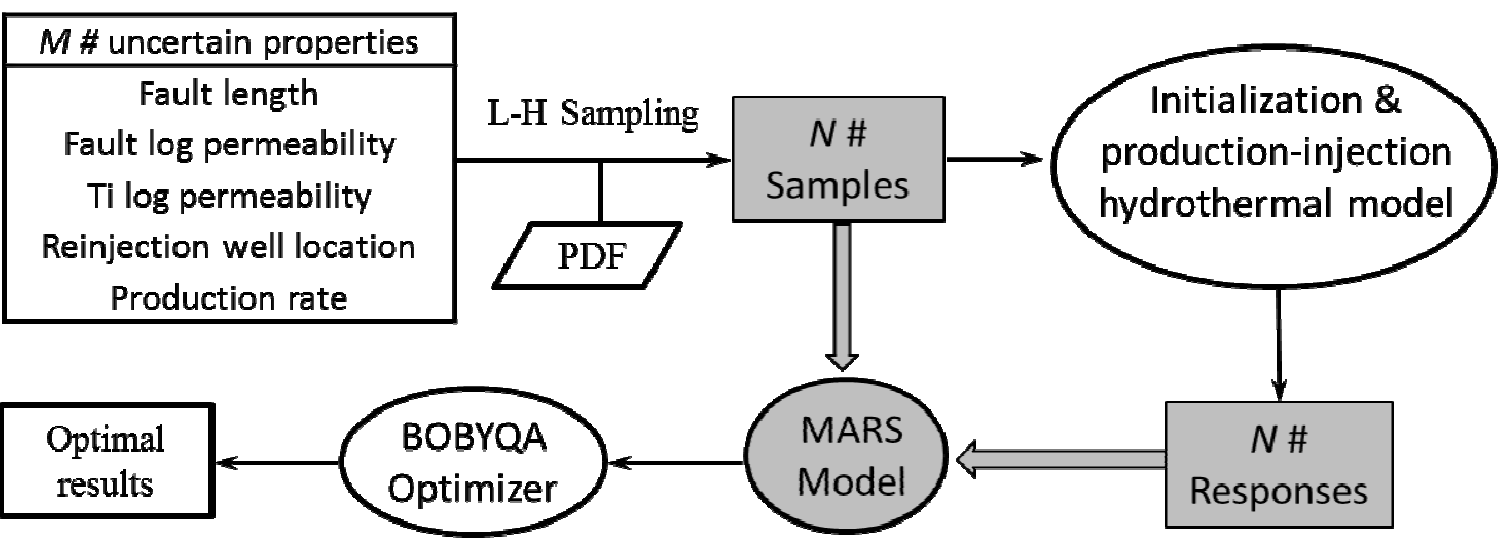

594 Figure 1. Schematic diagram of the MARS-based optimization framework. The gray shaded part shows that MARS models are trained by dataset generated from the 596 physical models. 


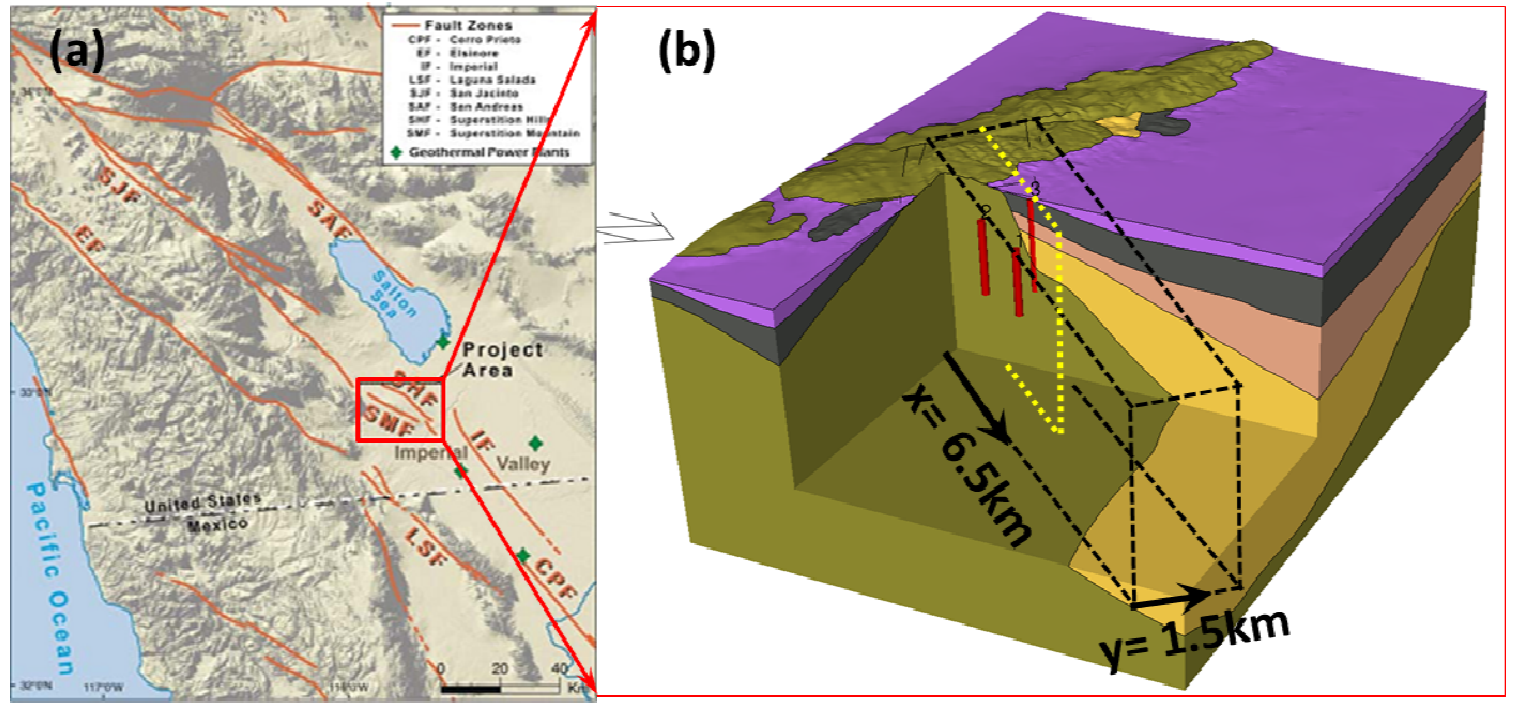

599 Figure 2. Superstition mountain geothermal prospect. (a) Location in Imperial

600 County, California, USA (Bjornastad et al. [26]); (b) Geological model looking from

601 the Northeast, and showing (from bottom) the granite basement, sandstone $\mathrm{Ti}$, and

602 three alluvial units Tp2, Tp1, and Qb (Figure3b). Dashed outline illustrates 3D core

603 domain of hydrothermal models. The dashed yellow plane represents the fault plane.

604 The three red tubes represent Naval exploratory (NAFEC) boreholes developed for

605 the geothermal prospect. Modified from Chen et al. [18].

606

607

608

609 

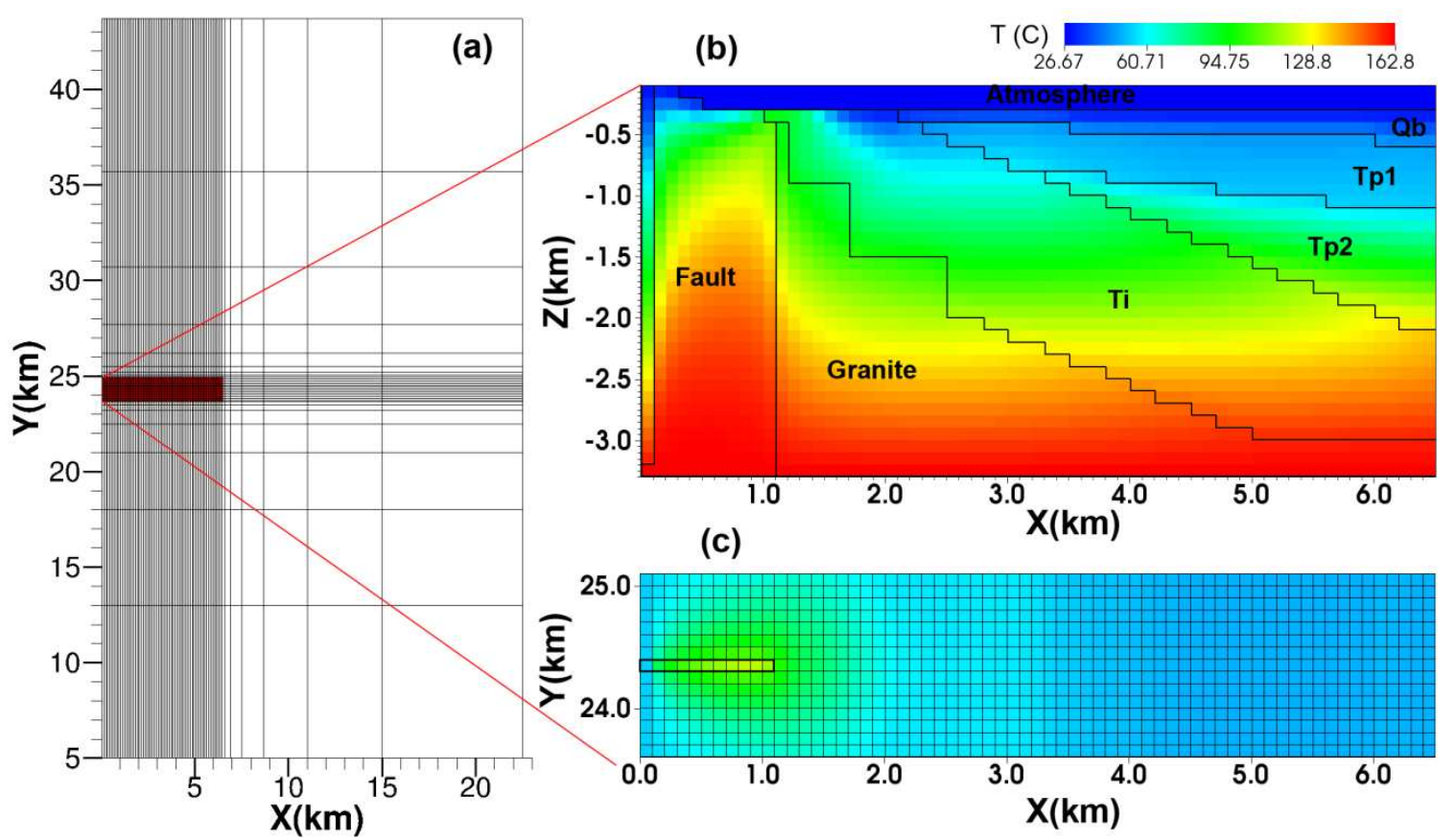

(c)

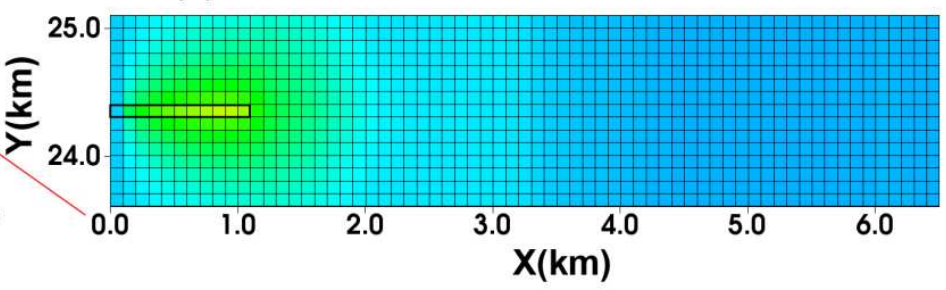

611 Figure 3. Hydrothermal model domain showing (a) Far field and core area (red 612 shaded area); (b) vertical slice of core domain at $\mathbf{Y}=\mathbf{2 8} \mathbf{k m}$, where the conjugate

613 fault crosses; (c) horizontal slice of core domain at depth $Z=800 \mathrm{~m}$, where the

614 production and injection wells are perforated. The fault height and length, and the

615 temperature distribution correspond to the input parameter set listed in Table 1.

616 Adapted from Chen et al. [18]. 


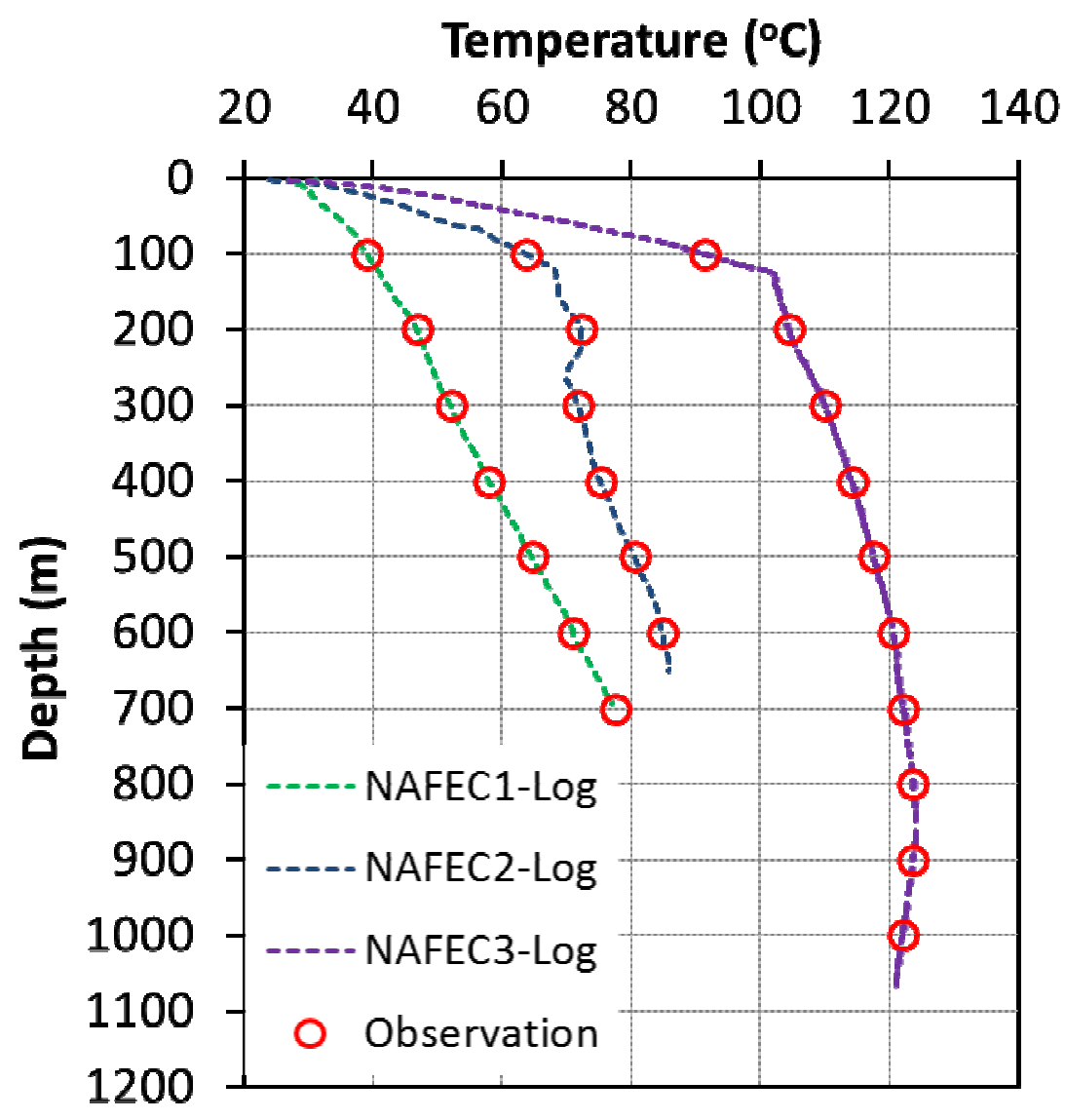

619

Figure 4. Measured temperature profiles along the three "NAFEC" boreholes

621

622

623 (Tiedeman et al., 2001) [27]. The red circle marks indicate the discrete locations along the measured data curves used as observations in the Bayesian inversion process. 

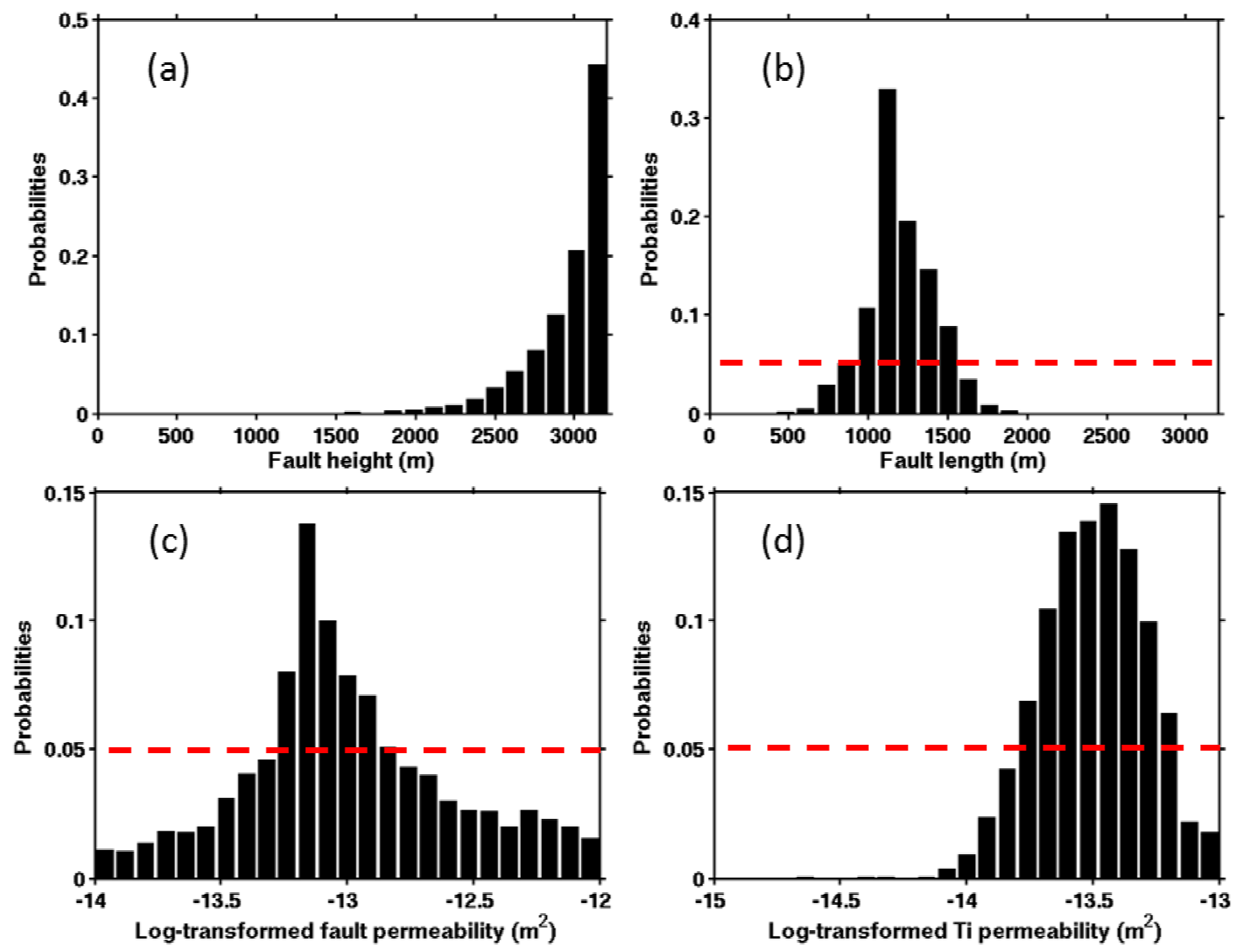

Figure 5. Posterior distribution of (a) fault height, (b) fault length, (c) fault permeability, (d) Ti permeability, which are inferred from Bayesian inversion by Chen et al. [18]. The red dashed line indicates $5 \%$ probability, which helps to determine the narrowed ranges of parameters used in optimizations.

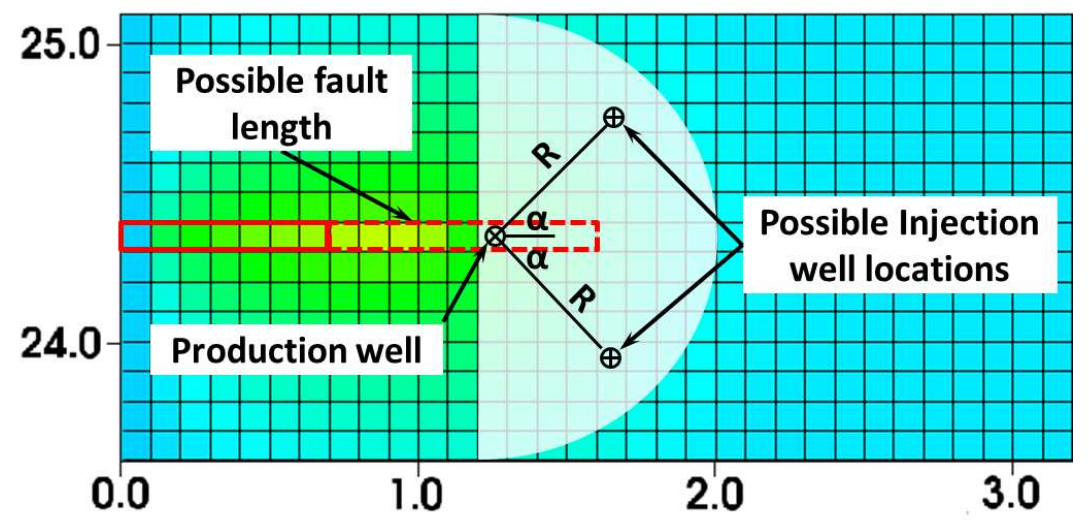

Figure 6. Reinjection-production scheme design. Fault length ranges from 0.8 to 1.6 $\mathrm{km}$. The production well location is fixed while the locations (radial distance $R$ and azimuth $\alpha$ ) of two symmetric injection wells are to be determined within semicircle gray area. Both production and injection wells are perforated $100 \mathrm{~m}$ in length at depth of $800 \mathrm{~m}$. The background is the temperature contour as shown in Figure $3 \mathrm{c}$. 

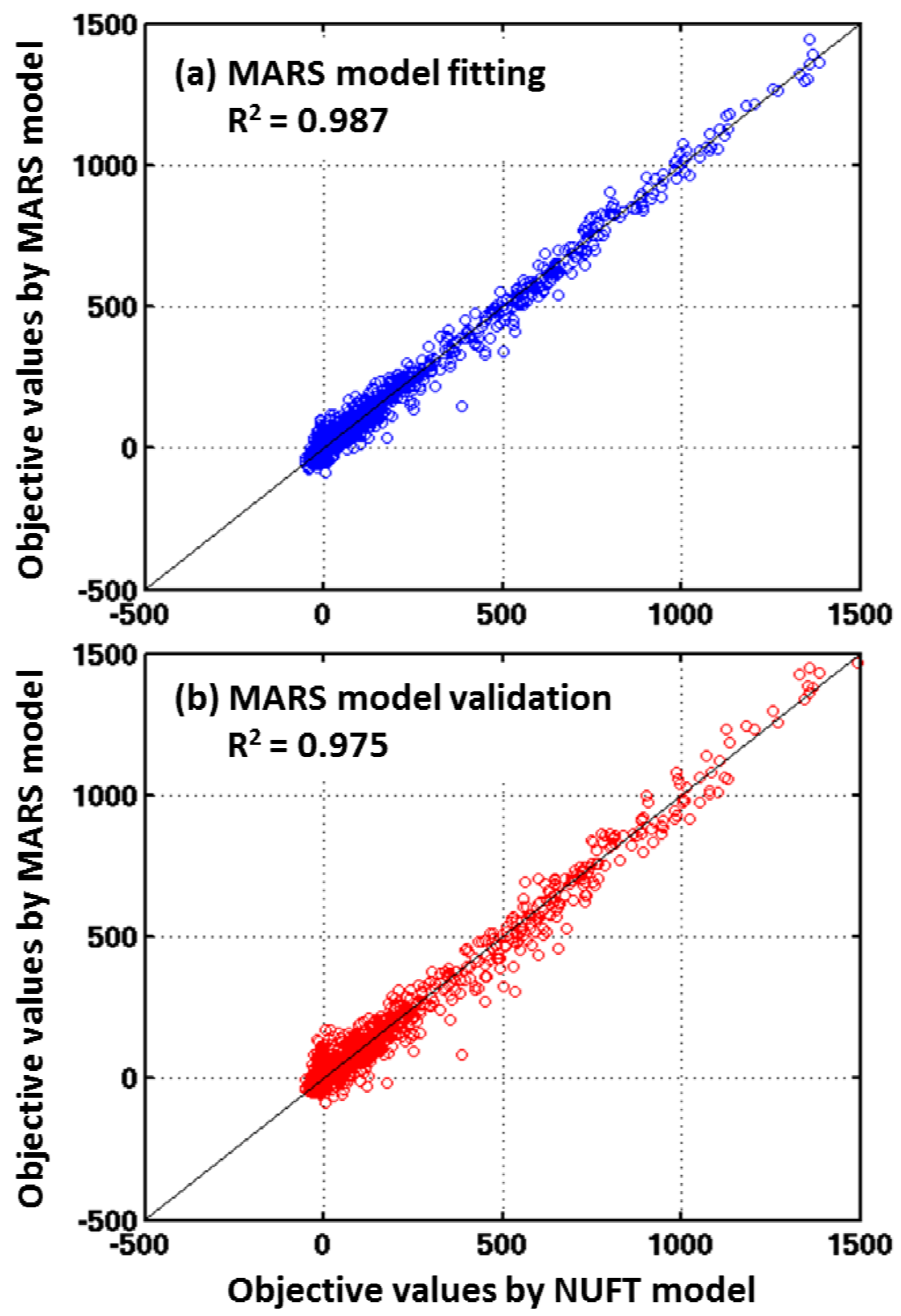

638 Figure 7. Scatter plots of objective function calculated from surrogate MARS model 639 data versus NUFT hydrothermal model from 1000 input samples for (a) MARS 640 model fitting, and (b) MARS model cross-validation. 


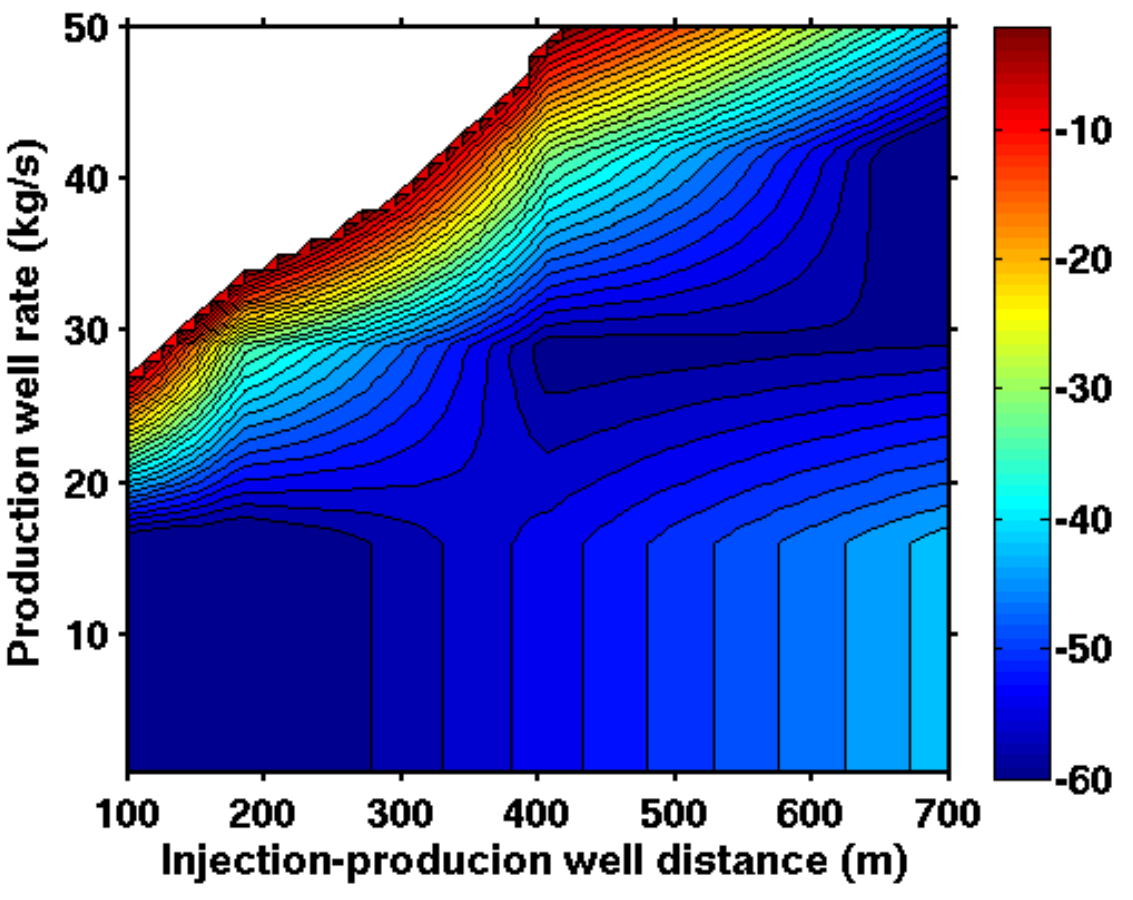

643 Figure 8. The visualized 2D response surface of objective function (-NPV)

644 corresponding to injection-production well distance and production rate in case 5.

645 White area indicates positive objective function, that is, negative NPV. 

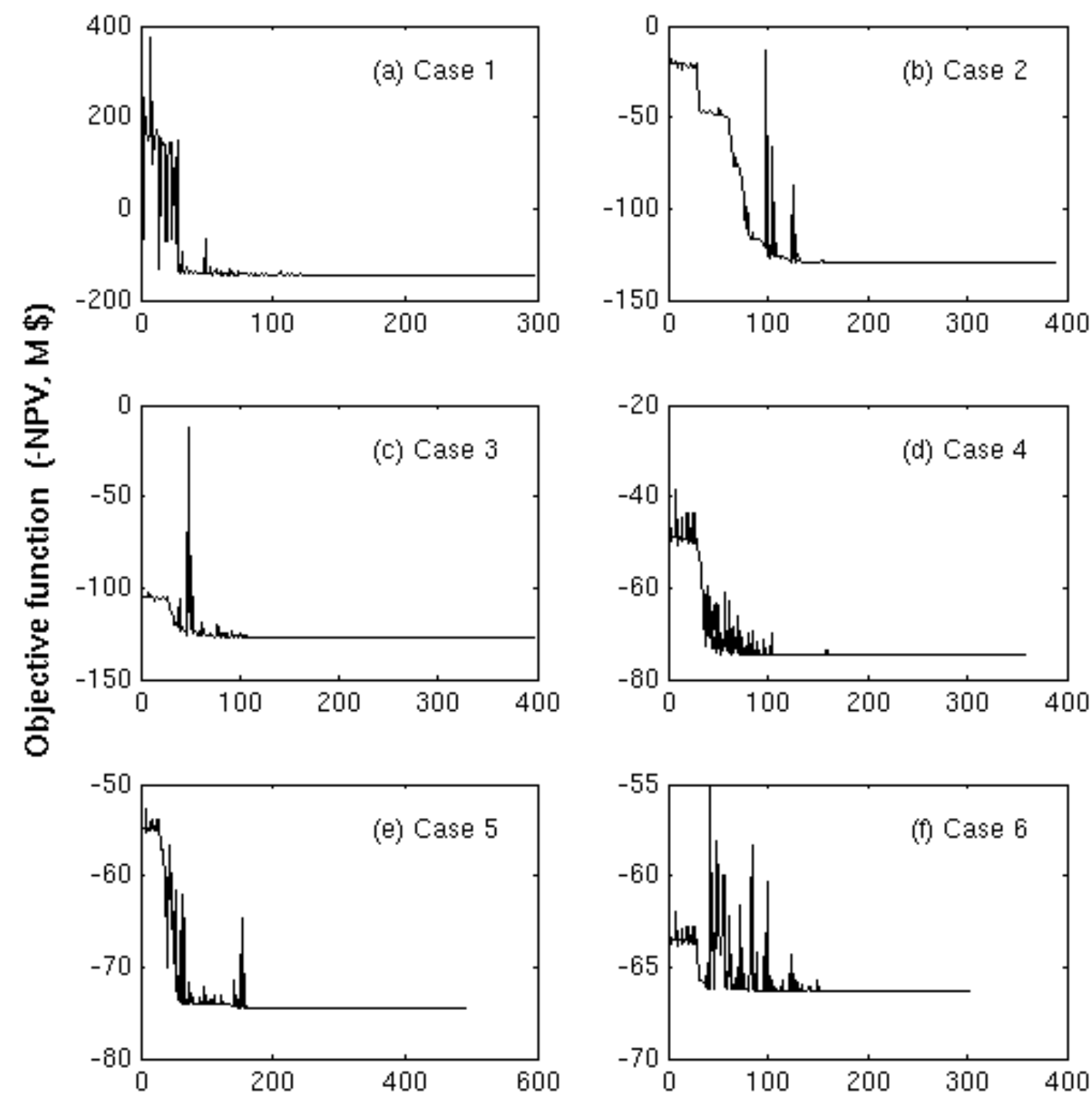

Model evaluations

648 Figure 9. Minimum objective function (i.e., maximum NPV after 50 years of 649 operation) searching curve for (a) Case 1 with 6 uncertain parameters, (b) Case 2 650 with 5 uncertain parameters, (c) Case 3 with 4 uncertain parameters, (d) Case 4 651 with 3 uncertain parameters, (e) Case 5 with 2 uncertain parameters, (f) Case 6 with 6521 uncertain parameter. The number of model evaluations and optimal parameter 653 values for the 6 cases are presented in Table 2. 


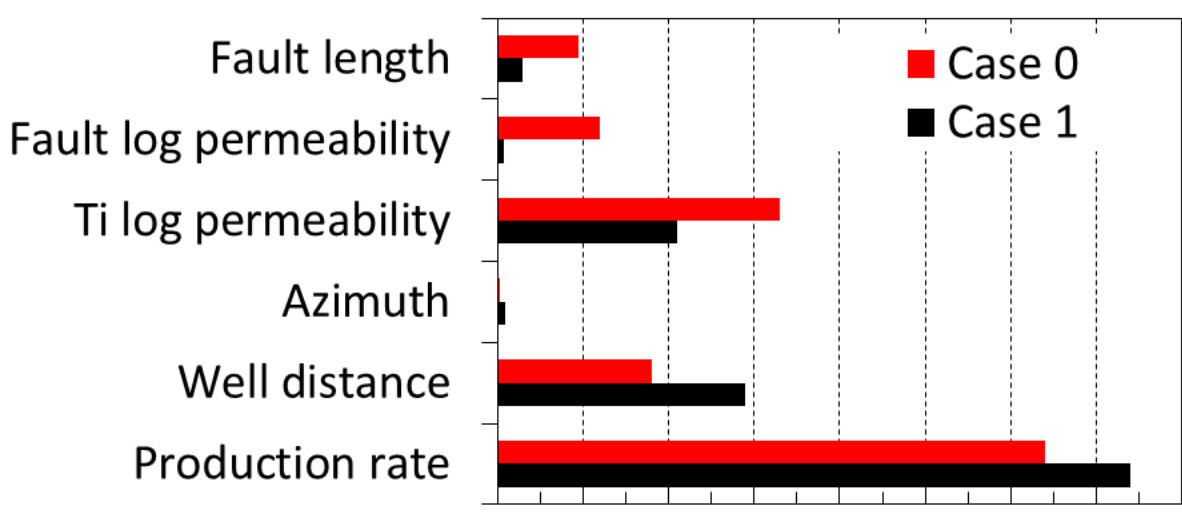

$\begin{array}{lllllllll}0 & 0.1 & 0.2 & 0.3 & 0.4 & 0.5 & 0.6 & 0.7 & 0.8\end{array}$

656 Figure 10. Comparison of sensitivity of objective function to 6 uncertain input parameters are constrained by prior and posterior information of a Bayesian inversion by Chen et al. [18]. The sensitivity is measured by Sobol' total order sensitivity indices. The range and optimal value of the 6 parameters are presented in Table 3. 

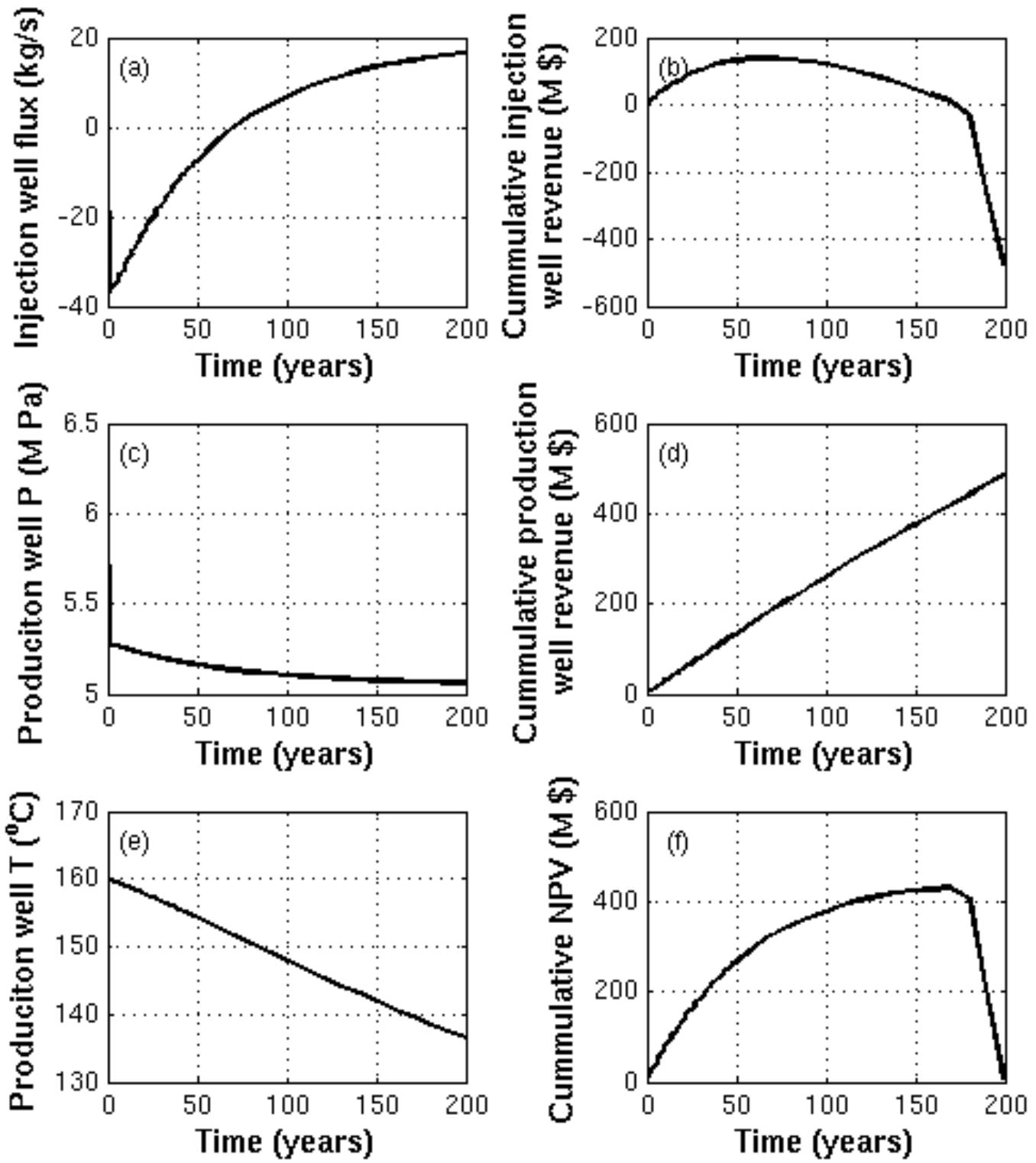

Figure 11. Plots of history simulated using the optimal parameter set from optimization Case 0 (denoted as Simulation 0). The left column shows (a) flux in injection wells with fixed bottom pressure, resulting extraction at the beginning, (c) production well bottom pressure with fixed rate, and (e) production well bottom temperature. The right column shows cumulative (b) revenue from injection wells, (d) revenue from production well, and (f) net profit value. 

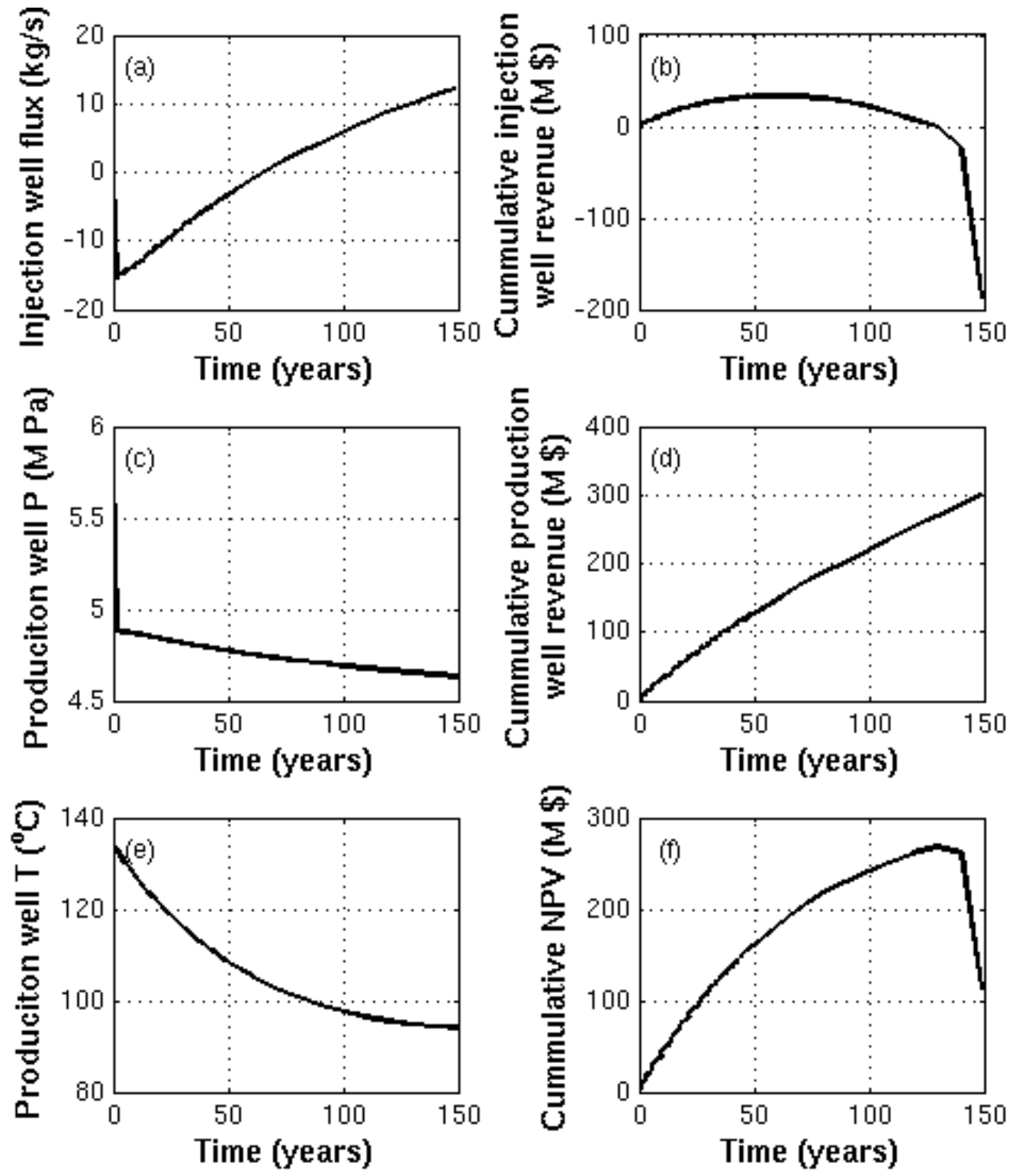

Figure 12. Plots of history simulated using the optimal parameter set from optimization Case 1 (denoted as Simulation 1). The left column shows (a) flux in injection wells with fixed bottom pressure, resulting extraction at the beginning, (c) production well bottom pressure with fixed rate, and (e) production well bottom temperature. The right column shows cumulative (b) revenue from injection wells, 

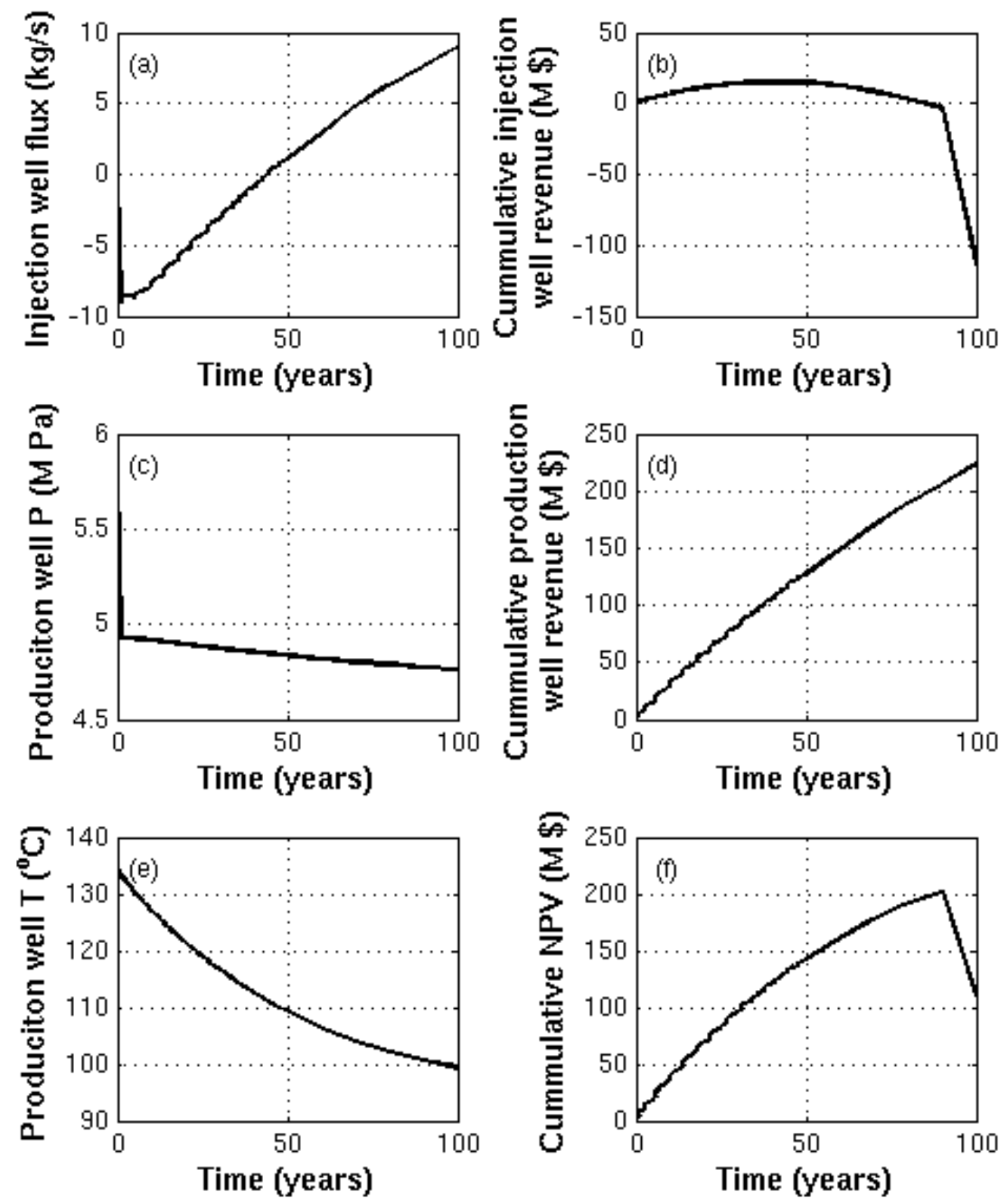

679 Figure 13. Plots of history with fixed injection well pressure 0.1 MPa higher than that in Simulation 1 (denoted as Simulation 2). The left column shows (a) flux in injection wells with fixed bottom pressure, resulting extraction at the beginning, (c) production well bottom pressure with fixed rate, and (e) production well bottom temperature. The right column shows cumulative (b) revenue from injection wells, 